\title{
Clinical Study \\ Development of a Score Predicting Survival after Palliative Reirradiation
}

\author{
Carsten Nieder, ${ }^{1,2}$ Nicolaus Andratschke, ${ }^{3}$ Kent Angelo, ${ }^{1}$ \\ Ellinor Haukland, ${ }^{1}$ and Anca L. Grosu ${ }^{4}$ \\ ${ }^{1}$ Department of Oncology and Palliative Medicine, Nordland Hospital, 8092 Bodø, Norway \\ ${ }^{2}$ Institute of Clinical Medicine, Faculty of Health Sciences, University of Tromsø, 9019 Tromsø, Norway \\ ${ }^{3}$ Department of Radiation Oncology, University Hospital Zurich, 8091 Zurich, Switzerland \\ ${ }^{4}$ Department of Radiation Oncology, University Hospital Freiburg, 79106 Freiburg, Germany
}

Correspondence should be addressed to Carsten Nieder; carsten.nieder@nlsh.no

Received 5 May 2014; Accepted 2 September 2014; Published 21 September 2014

Academic Editor: Thomas E. Adrian

Copyright (C) 2014 Carsten Nieder et al. This is an open access article distributed under the Creative Commons Attribution License, which permits unrestricted use, distribution, and reproduction in any medium, provided the original work is properly cited.

Purpose. To develop a prognostic model for predicting survival after palliative reirradiation (PR). Methods and Materials. We analyzed all 87 PR courses administered at a dedicated palliative radiotherapy facility between 20.06.2007 (opening) and 31.12.2009. Uni- and multivariate survival analyses were performed, the previously published survival prediction score (SPS) was evaluated, and a PR-specific prognostic score was calculated. Results. In multivariate analysis, four parameters significantly influenced survival: performance status, use of steroids, presence of liver metastases, and pleural effusion. Based on these parameters, a 4-tiered score was developed. Median survival was 24.5 months for the favorable group, 9.7 and 2.8 months for the two intermediate groups, and 1.1 months for the unfavorable group $(P=0.019$ for comparison between the two favorable groups and $P \leq 0.002$ for all other pairwise comparisons). All patients in the unfavorable group died within 2 months. Conclusion. The performance of PR-specific score was promising and might facilitate identification of patients who survive long enough to benefit from PR. It should be validated in independent patient groups, ideally from several institutions and countries.

\section{Introduction}

Palliative reirradiation is currently used in a variety of clinical settings, including but not limited to bone and brain metastases or lung and gynecological cancers [1-4]. The number of scientific publications on this topic has increased in recent years [5]. In a well-defined geographical part of Norway, palliative reirradiation contributed $10 \%$ to all palliative radiotherapy series administered during a 12-month period [6]. Randomized trials comparing single versus multiple fractions for painful bone metastases reported retreatment rates of 11$42 \%$ after a single fraction and $0-24 \%$ after multiple fractions, as summarized by Chow et al. [1]. Comparable to palliative radiotherapy in general, clinicians attempt to tailor treatment regimens to patients' prognosis, thereby minimizing undesirable over- and undertreatment. Decision aids such as prognostic scores and nomograms might facilitate rapid and reproducible assessment of patients' survival expectation by transforming the complex set of patient- and disease-related prognostic factors into a standardized tool. Ideally, prognostic scores are easy to administer and valid across different institutions and countries [7]. The Survival Prediction Score (SPS), developed and validated by Chow et al. in patient cohorts treated with palliative radiotherapy, is among the tools that might be widely applicable, because it is based on three readily available parameters: primary cancer type, site of metastases, and performance status [8]. Its performance has never been tested specifically in patients undergoing palliative reirradiation. Together with a large number of other baseline factors potentially impacting survival, we analyzed SPS in a single-institution cohort study.

\section{Methods}

We retrospectively reviewed the records of all consecutive patients who received palliative reirradiation at a single 
hospital with dedicated palliative radiotherapy unit. The patients started their treatment in the time period from June 20, 2007 (date of opening of the dedicated palliative radiotherapy unit), to December 31, 2009. Reirradiation was defined as partial or complete field overlap (examples of partial overlap: initial course included thoracic vertebrae Th46 and reirradiation Th6-8; initial course of radical prostate radiotherapy followed by pelvic bone metastasis irradiation). A total of 87 reirradiation courses were studied. Stereotactic radiotherapy was unavailable and thus not included in the present series. All medical records, treatment details, and information on date of death were available in the hospital's electronic patient record (EPR) system. The survival status and date of death or last follow-up of the patients were obtained from the EPR. Patients who were lost to followup were censored on the date of last documented contact (personal appointment, telephone conversation, and blood test). Median follow-up for all surviving/censored patients was 5.4 months. Survival time was measured from the start of reirradiation. Actuarial survival curves were generated by Kaplan-Meier method and compared by log-rank test (analyses performed with IBM SPSS Statistics 20). Multivariate analyses were performed by Cox regression (backward conditional method). We assigned SPS as described by Chow et al. [8], that is, based on three variables (nonbreast cancer, metastases other than bone, and Karnofsky performance status (KPS) $\leq 60$ ): poor prognosis group when all three were present, intermediate prognosis group when two were present, and good prognosis group when $0-1$ were present. Our own prognostic scores were developed as previously described by Rades et al. $[9,10]$. In brief, the score for each predictive factor was determined by dividing the actuarial death rate at prespecified time points (given as the percentage) by 10. For example, patients with good KPS were assigned 0 points and those with poor KPS 1.5 points (rate of death at 1 month (15\%) divided by 10 ). The total score represented the sum of the scores for each predictive factor. Two time points reflecting poor prognosis or short survival were chosen, 1 month and 2 months, because there is no generally agreed definition of sufficient survival expectation, justifying initiation of palliative radiotherapy. Given that recent research and discussions focused on overtreatment, for example, use of radiation therapy in the last 30 days of life, we felt that predicting short survival might be more important [11-14].

\section{Results}

Median age at the time of reirradiation was 67 years (range $38-90$ years). Prostate (29\%) and non-small cell lung cancer (NSCLC, 11\%) were the most common primary tumors. Additional baseline information is shown in Table 1. Bone metastases were the prevailing target for reirradiation. The most common regime consisted of 10 fractions of $3 \mathrm{~Gy}$ (43\%). Other common regimes included $8 \mathrm{~Gy}$ single fraction (uncomplicated bone metastases) and 5 fractions of $4 \mathrm{~Gy}$ (various sites and indications). Five courses (6\%) remained incomplete, typically because of earlier than expected clinical

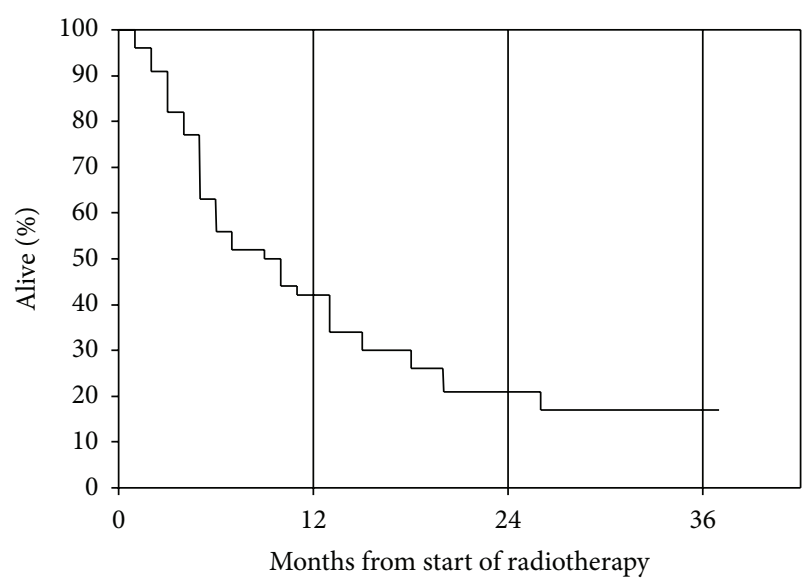

FIgURE 1: Actuarial overall survival after palliative reirradiation (Kaplan-Meier estimate).

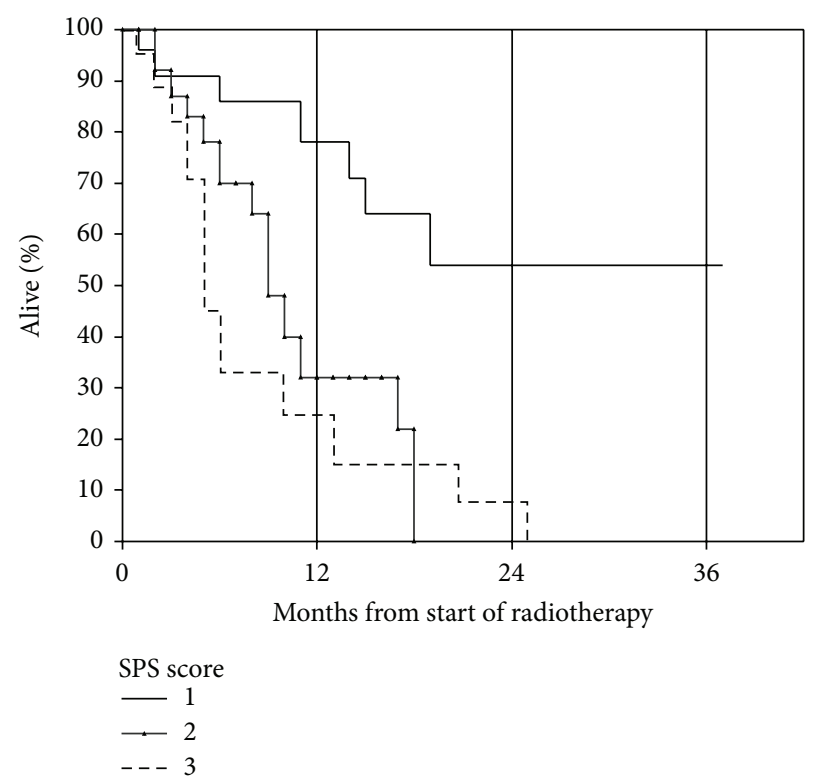

FIGURE 2: Actuarial overall survival after palliative reirradiation stratified by SPS score (Kaplan-Meier estimate): group $1(n=23)$, median not reached; group $2(n=26)$, median 6.7 months; group $3(n=38)$, median 4.1 months; $P=0.26$ for group 2 versus 3 and $P<0.05$ for other comparisons.

deterioration. Median survival of this small group of patients was 2.8 months. Overall median survival from reirradiation was 8.6 months and 1-year survival rate $42 \%$ (Figure 1). Six percent of patients received radiotherapy during the final month of life. Seventeen percent of patients died within 2 months.

We analyzed the potential prognostic impact of all baseline parameters shown in Table 1 and assigned SPS score. However, the performance of this score was unsatisfactory because two of the three patient groups had similar survival (Figure 2). As shown in Table 2, two components of the SPS score (metastases location and performance status) significantly influenced survival, while primary tumor type 
TABLE 1: Patient characteristics.

\begin{tabular}{|c|c|c|}
\hline Characteristic & No. & $\%$ \\
\hline Entire cohort & 87 & \\
\hline \multicolumn{3}{|l|}{ Gender } \\
\hline Male & 65 & 75 \\
\hline Female & 22 & 25 \\
\hline \multicolumn{3}{|l|}{ Family status $^{1}$} \\
\hline Single & 20 & 23 \\
\hline Married & 55 & 63 \\
\hline Partner & 5 & 6 \\
\hline Missing information & 7 & 8 \\
\hline \multicolumn{3}{|l|}{ Karnofsky performance status } \\
\hline $90-100$ & 31 & 36 \\
\hline $70-80$ & 30 & 34 \\
\hline$\leq 60$ & 26 & 30 \\
\hline \multicolumn{3}{|l|}{ Primary tumor site } \\
\hline Prostate & 25 & 29 \\
\hline Breast & 9 & 10 \\
\hline Lung (non-small cell) & 10 & 11 \\
\hline Colorectal & 8 & 9 \\
\hline Bladder & 5 & 6 \\
\hline Kidney & 6 & 7 \\
\hline Skin (malignant melanoma) & 3 & 3 \\
\hline Other & 21 & 24 \\
\hline \multicolumn{3}{|l|}{ Dose/fractionation (intention-to-treat) } \\
\hline 10 fractions of $3 \mathrm{~Gy}$ & 24 & 28 \\
\hline Single fraction of $8 \mathrm{~Gy}$ & 19 & 22 \\
\hline 5 fractions of $4 \mathrm{~Gy}$ & 15 & 17 \\
\hline $12-15$ fractions of $2.5 \mathrm{~Gy}$ & 4 & 5 \\
\hline Other & 25 & 29 \\
\hline \multicolumn{3}{|l|}{ Reirradiation target types } \\
\hline Bone metastases & 69 & 79 \\
\hline Brain metastases & 5 & 6 \\
\hline Lung metastases or primary tumor & 6 & 7 \\
\hline Other & 7 & 8 \\
\hline \multicolumn{3}{|l|}{ Known brain metastases } \\
\hline No & 80 & 92 \\
\hline One or more & 7 & 8 \\
\hline \multicolumn{3}{|l|}{ Known liver metastases } \\
\hline No & 68 & 78 \\
\hline One or more & 19 & 22 \\
\hline \multicolumn{3}{|l|}{ Known lung metastases } \\
\hline No & 65 & 75 \\
\hline One or more & 22 & 25 \\
\hline \multicolumn{3}{|l|}{ Known adrenal gland metastases } \\
\hline No & 76 & 87 \\
\hline One or more & 11 & 13 \\
\hline \multicolumn{3}{|l|}{ Known bone metastases } \\
\hline No & 14 & 16 \\
\hline One or more & 73 & 84 \\
\hline \multicolumn{3}{|l|}{ Metastatic spinal cord compression } \\
\hline No & 80 & 92 \\
\hline Yes (radiologic or symptomatic) & 7 & 8 \\
\hline \multicolumn{3}{|l|}{ Pleural effusion } \\
\hline No & 81 & 93 \\
\hline Yes (radiologic or symptomatic) & 6 & 7 \\
\hline
\end{tabular}

TABle 1: Continued.

\begin{tabular}{|c|c|c|}
\hline Characteristic & No. & $\%$ \\
\hline \multicolumn{3}{|l|}{ Number of metastatic sites } \\
\hline 0 & 10 & 11 \\
\hline 1 (e.g., lungs only) & 37 & 43 \\
\hline 2 (e.g., lungs and brain) & 27 & 31 \\
\hline 3 & 11 & 13 \\
\hline 4 & 2 & 2 \\
\hline \multicolumn{3}{|c|}{ Progressive disease outside RT target volume ${ }^{1}$} \\
\hline No & 27 & 31 \\
\hline Yes & 55 & 63 \\
\hline Missing information & 5 & 6 \\
\hline \multicolumn{3}{|l|}{ Systemic cancer treatment ${ }^{1}$} \\
\hline No & 23 & 26 \\
\hline Within 4 weeks before RT & 21 & 24 \\
\hline Within 3 months before RT & 14 & 16 \\
\hline Earlier & 17 & 20 \\
\hline Missing information & 12 & 14 \\
\hline \multicolumn{3}{|l|}{ Use of opioid analgetics at start of $\mathrm{RT}^{1}$} \\
\hline No & 21 & 24 \\
\hline Yes & 54 & 62 \\
\hline Missing information & 12 & 14 \\
\hline \multicolumn{3}{|l|}{ Use of steroids at start of $\mathrm{RT}^{1}$} \\
\hline No & 32 & 37 \\
\hline Yes & 38 & 44 \\
\hline Missing information & 17 & 20 \\
\hline \multicolumn{3}{|l|}{ Serum hemoglobin ${ }^{1}$} \\
\hline Low $^{2}$ & 66 & 76 \\
\hline Normal & 16 & 18 \\
\hline Missing information & 5 & 6 \\
\hline \multicolumn{3}{|l|}{ Serum albumin ${ }^{1}$} \\
\hline Low $^{2}$ & 17 & 20 \\
\hline Normal & 42 & 48 \\
\hline Missing information & 28 & 32 \\
\hline \multicolumn{3}{|l|}{ Serum lactate dehydrogenase ${ }^{1}$} \\
\hline Normal $^{2}$ & 14 & 16 \\
\hline Elevated & 35 & 40 \\
\hline Missing information & 38 & 44 \\
\hline \multicolumn{3}{|l|}{ Serum alkaline phosphatase ${ }^{1}$} \\
\hline Normal $^{2}$ & 25 & 29 \\
\hline Elevated & 29 & 33 \\
\hline Missing information & 33 & 38 \\
\hline \multicolumn{3}{|l|}{ Serum creatinine $e^{1}$} \\
\hline Low $^{2}$ & 13 & 15 \\
\hline Normal & 48 & 55 \\
\hline Elevated & 15 & 17 \\
\hline Missing information & 11 & 13 \\
\hline \multicolumn{3}{|l|}{ Serum C-reactive protein ${ }^{1}$} \\
\hline Normal $^{2}$ & 20 & 23 \\
\hline Elevated but less than $30 \mathrm{mg} / \mathrm{L}$ & 27 & 31 \\
\hline Elevated $30-60 \mathrm{mg} / \mathrm{L}$ & 14 & 16 \\
\hline Elevated $>60 \mathrm{mg} / \mathrm{L}$ & 17 & 20 \\
\hline Missing information & 9 & 10 \\
\hline \multicolumn{3}{|l|}{ Thrombocyte count ${ }^{1}$} \\
\hline Low $^{2}$ & 11 & 13 \\
\hline Normal & 45 & 52 \\
\hline High & 19 & 22 \\
\hline Missing information & 12 & 14 \\
\hline
\end{tabular}


TABLE 1: Continued.

\begin{tabular}{lcc}
\hline Characteristic & No. & $\%$ \\
\hline Charlson comorbidity index $^{1}$ & & \\
0 & 7 & 8 \\
$1-2$ & 44 & 51 \\
3 or more & 28 & 32 \\
$\quad$ Missing information & 8 & 9 \\
Smoking status $^{1}$ & & \\
$\quad$ Current smoker & 34 & 39 \\
No & 34 & 39 \\
Missing information & 19 & 22 \\
\hline
\end{tabular}

$\mathrm{RT}$ : radiotherapy.

${ }^{1}$ Missing information in some cases.

${ }^{2}$ Hematology and blood chemistry results refer to institutional limits of normal; only test results obtained within one week before RT were considered.

did not. In multivariate analysis, a total of four parameters significantly influenced survival: KPS, use of steroids, presence of liver metastases, and pleural effusion. Based on these parameters, a new 4-tiered prognostic score was developed. As described in Section 2, we compared two different variants, which are shown in Table 3. When applying a short-survival-definition of 1 month (variant 1), the resulting survival curves separated clearly (Figure 3). Median survival was 24.5 months for the favorable group, 9.7 and 2.8 months for the intermediate groups, and 1.1 months for the unfavorable group $(P=0.024$ for comparison between the two favorable groups and $P \leq 0.003$ for all other pair-wise comparisons). Thirty-three percent of patients in the unfavorable group died within 1 month and all within 2 months. When applying a short-survival-definition of 2 months (variant 2), the resulting survival curves separated equally clear (Figure 4). Median survival was exactly the same as in variant $1(P=0.019$ for comparison between the two favorable groups and $P \leq 0.002$ for all other pair-wise comparisons). Since the unfavorable group included exactly the same patients, 33\% died within 1 month and all within 2 months. Because of its superior significance level, variant 2 might be the preferred assignment method.

\section{Discussion}

Palliative reirradiation is an important treatment option, providing symptom improvement in many patients with bone metastases [1] and other conditions [15]. While most previous studies were small and often retrospective, the randomized bone metastases study by Chow et al. comparing different fractionation regimens included 850 patients [1]. Median survival in the two arms was 9.3 and 9.7 months, respectively. This result is comparable to the 8.6 months reported in our own, bone metastases-dominated study. However, survival of individual patients might be as short as few days or as long as several years (Figure 1). Therefore, prognostic scores might be valuable decision aids when prescribing palliative reirradiation. Chow et al. have previously published several reports on a score for patients receiving palliative radiotherapy in general, the SPS. Development of this prediction model started in

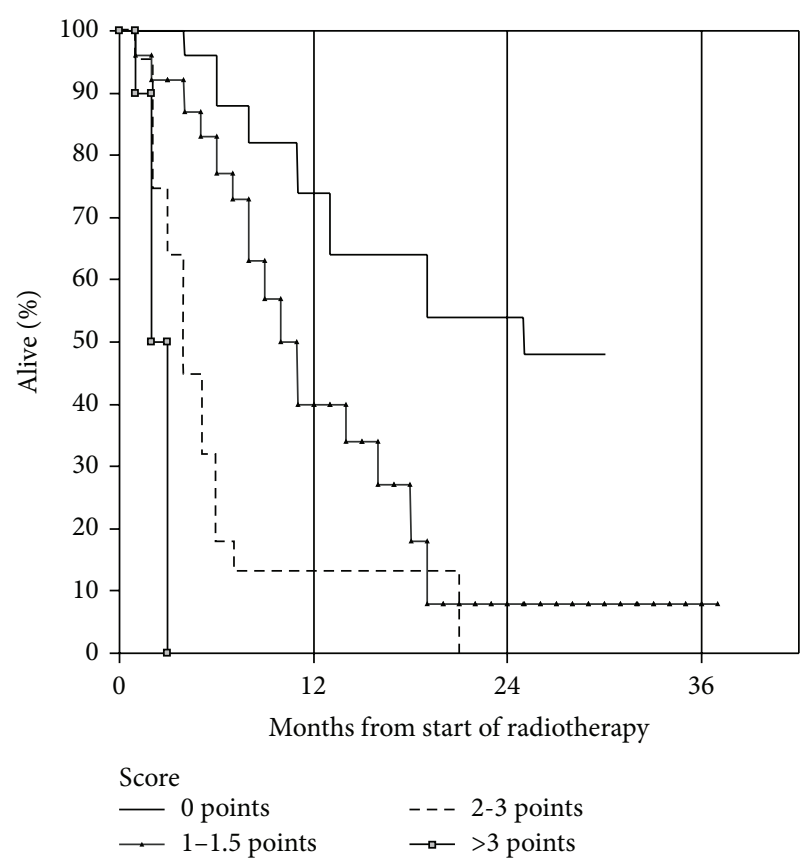

FIGURE 3: Actuarial overall survival after palliative reirradiation stratified by new score, variant 1 (Kaplan-Meier estimate): median 24.5 (0 points) versus 9.7 (1-1.5 points) versus 2.8 (2-3 points) versus 1.1 months ( $>3$ points), $P=0.024$ for comparison between group 1 and $2, P \leq 0.003$ for all other pair-wise comparisons. Number of patients in each group: 20,24,20, and 6. Missing information to assign score in 17 patients.

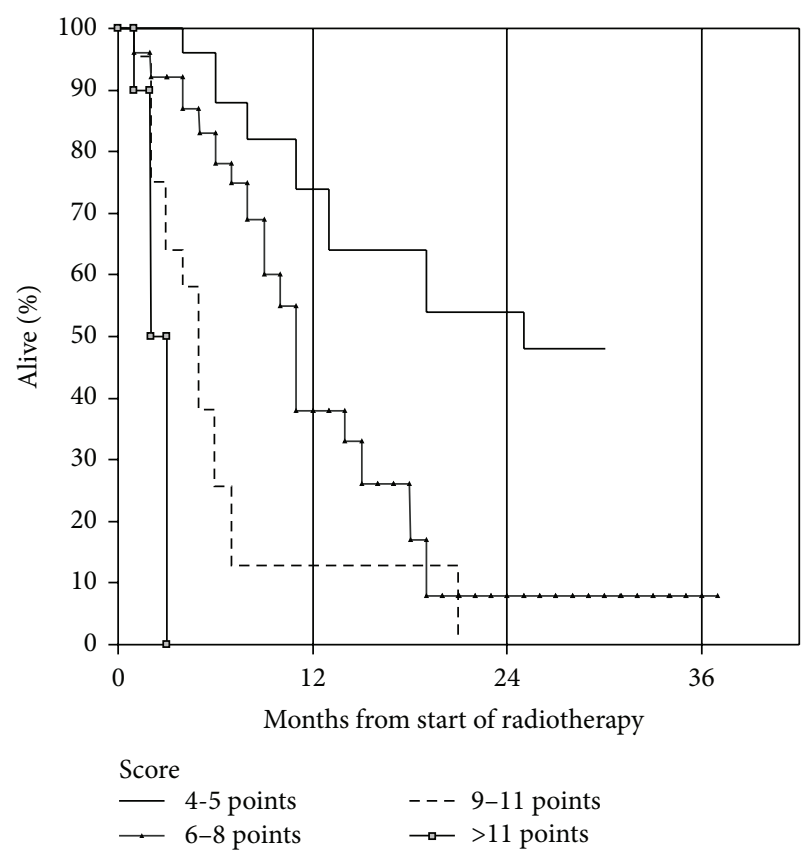

FIGURE 4: Actuarial overall survival after palliative reirradiation stratified by new score, variant 2 (Kaplan-Meier estimate): median 24.5 (4-5 points) versus 9.7 (6-8 points) versus 2.8 (9-11 points) versus 1.1 months ( $>11$ points), $P=0.019$ for comparison between group 1 and $2, P \leq 0.002$ for all other pair-wise comparisons. Number of patients in each group: 20, 26, 18, and 6. Missing information to assign score in 17 patients. 
TABle 2: Prognostic factors for survival. All baseline variables shown in Table 1 were analyzed (univariate, log-rank test). Those with $P$ value $<0.1$ were carried forward to multivariate Cox regression analysis and are shown here.

\begin{tabular}{|c|c|c|c|}
\hline \multirow{2}{*}{ Characteristic } & \multirow{2}{*}{ Median survival (months) } & \multicolumn{2}{|c|}{$P$ value } \\
\hline & & Univariate $^{1}$ & Multivariate \\
\hline \multicolumn{4}{|l|}{ Karnofsky PS } \\
\hline $90-100$ & 18.3 & \multirow{3}{*}{0.0001} & \multirow{3}{*}{0.0001} \\
\hline $70-80$ & 9.4 & & \\
\hline$\leq 60$ & 2.1 & & \\
\hline \multicolumn{4}{|l|}{ Known brain metastases } \\
\hline No & 9.7 & \multirow{2}{*}{0.008} & \multirow{2}{*}{ n.s. } \\
\hline Yes & 3.6 & & \\
\hline \multicolumn{4}{|l|}{ Known liver metastases } \\
\hline No & 9.7 & \multirow{2}{*}{0.037} & \multirow{2}{*}{0.039} \\
\hline Yes & 2.8 & & \\
\hline \multicolumn{4}{|l|}{ Pleural effusion } \\
\hline No & 9.4 & \multirow{2}{*}{0.007} & \multirow{2}{*}{0.039} \\
\hline Yes & 1.3 & & \\
\hline \multicolumn{4}{|l|}{ Number of metastatic sites } \\
\hline Max. 2 & 9.7 & \multirow{2}{*}{0.054} & \multirow{2}{*}{ n.s. } \\
\hline 3 or more & 2.8 & & \\
\hline \multicolumn{4}{|c|}{ Progressive disease outside RT target volume } \\
\hline No & 12.6 & \multirow{2}{*}{0.033} & \multirow{2}{*}{ n.s. } \\
\hline Yes & 5.5 & & \\
\hline \multicolumn{4}{|l|}{ Use of opioid analgetics } \\
\hline No & 24.5 & 002 & $\mathrm{~ns}$ \\
\hline Yes & 5.2 & 0.02 & 111.0. \\
\hline Use of steroids & & & \\
\hline No & 12.2 & 0.002 & 0.015 \\
\hline Yes & 3.6 & & \\
\hline Serum albumin & & & \\
\hline Low & 9.7 & 0001 & $n_{s}$ \\
\hline Normal & 2.8 & 0.001 & 11.5. \\
\hline Serum alkaline phosphatase & & & \\
\hline Normal & 15.1 & 0.027 & $n_{s}$ \\
\hline Elevated & 4.1 & 0.021 & 11.3. \\
\hline Serum creatinine & & & \\
\hline Low & 1.6 & & \\
\hline Normal & 9.7 & 0.0001 & n.s. \\
\hline Elevated & 15.1 & & \\
\hline Serum C-reactive protein & & & \\
\hline Normal & 18.3 & & \\
\hline Elevated but less than $30 \mathrm{mg} / \mathrm{L}$ & 12.6 & 00001 & $\mathrm{~ns}_{\mathrm{s}}$ \\
\hline Elevated $30-60 \mathrm{mg} / \mathrm{L}$ & 5.3 & 0.0001 & n.s. \\
\hline Elevated $>60 \mathrm{mg} / \mathrm{L}$ & 2.6 & & \\
\hline Thrombocyte count & & & \\
\hline Low & 12.7 & & \\
\hline Normal & 9.7 & 0.038 & n.s. \\
\hline High & 4.0 & & \\
\hline Number of abnormal blood tests ${ }^{2}$ & & & \\
\hline Max. 1 & 12.7 & & \\
\hline 2 & 5.8 & 0.008 & n.s. \\
\hline 3 or more & 3.0 & & \\
\hline
\end{tabular}


TABLe 2: Continued.

\begin{tabular}{|c|c|c|c|}
\hline \multirow{2}{*}{ Characteristic } & \multirow{2}{*}{ Median survival (months) } & \multicolumn{2}{|c|}{$P$ value } \\
\hline & & Univariate $^{1}$ & Multivariate \\
\hline \multicolumn{4}{|l|}{ Smoking status } \\
\hline Current smoker & 4.3 & \multirow{2}{*}{0.063} & \multirow{2}{*}{ n.s. } \\
\hline No & 9.7 & & \\
\hline \multicolumn{4}{|l|}{ Time from first cancer diagnosis } \\
\hline Shorter than median (47 months) & 5.3 & \multirow{2}{*}{0.089} & \multirow{2}{*}{ n.s. } \\
\hline Longer than median & 9.7 & & \\
\hline
\end{tabular}

RT: radiotherapy; PS: performance status.

${ }^{1}$ If more than 2 groups, $P$ value from log-rank test pooled over all strata.

${ }^{2}$ All tests shown in Table 1 were considered.

Significance levels were not corrected for multiple tests.

TABLE 3: Prognostic scores based on four parameters predicting survival in multivariate analysis. Endpoints: death within 1 month (variant 1) and death within 2 months (variant 2).

\begin{tabular}{|c|c|c|c|c|}
\hline Parameter & Died within 1 month & Points $^{\top}$ & Died within 2 months & Points $^{1}$ \\
\hline \multicolumn{5}{|l|}{ Karnofsky PS } \\
\hline $70-100$ & $2 \%$ & 0 & $7 \%$ & 1 \\
\hline$\leq 60$ & $15 \%$ & 1.5 & $39 \%$ & 4 \\
\hline \multicolumn{5}{|l|}{ Known liver metastases } \\
\hline No & $4 \%$ & 0 & $8 \%$ & 1 \\
\hline Yes & $11 \%$ & 1 & $49 \%$ & 5 \\
\hline \multicolumn{5}{|l|}{ Pleural effusion } \\
\hline No & $4 \%$ & 0 & $14 \%$ & 1 \\
\hline Yes & $33 \%$ & 3 & $50 \%$ & 5 \\
\hline \multicolumn{5}{|l|}{ Use of steroids } \\
\hline No & $3 \%$ & 0 & $10 \%$ & 1 \\
\hline Yes & $11 \%$ & 1 & $28 \%$ & 3 \\
\hline Minimum sum score & & 0 & & 4 \\
\hline Maximum sum score & & 6.5 & & 17 \\
\hline
\end{tabular}

PS: performance status.

${ }^{1}$ Death rate divided by 10 .

395 patients referred to their palliative radiotherapy program [16]. Later, they refined their original six-parameter-model by reducing the number of variables to three (primary cancer type, site of metastases, and performance status), arriving at the SPS $[8,17]$. We hypothesized that this score might also predict survival of patients receiving reirradiation but discovered that further studies, which also include other models, are needed. The performance of the SPS score (Figure 2) can be explained by the fact that not all adverse SPS features (nonbreast cancer, metastases other than bone, and poor performance status) influenced prognosis of reirradiated patients. In the present study, metastases location and performance status significantly influenced survival, while primary tumor type did not.

Disadvantages of our study include its retrospective design and limited number of patients, especially regarding subgroups. Not all patients had complete information on all baseline parameters recorded in the EPR system. The majority of reirradiation courses consisted of hypofractionated regimens, mostly 1-15 fractions, with dose/fractionation parameters reflecting a patient's expected prognosis (clinical estimate). We did not use any particular prognostic models or scores when assigning treatment regime during the time period covered in our study. Nevertheless, more than $90 \%$ of patients who were offered reirradiation also completed their treatment. Only $6 \%$ were treated during the final month of life, suggesting that our clinical decision making was largely successful, even if further improvement should be attempted.

Our score based on KPS, use of steroids, presence of liver metastases, and pleural effusion performed promisingly. To the best of our knowledge, no other scores related specifically to palliative reirradiation exist. One of the clinical aims of applying prognostic scores might be avoidance of overtreatment in patients with very short survival [18]. Recently, Tanvetyanon et al. have reported on use of radiotherapy in the last 30 days of life in the United States [19]. They used a SEERMedicare linked database to obtain a large study cohort of 202,299 patients who died as a result of lung, breast, prostate, colorectal, and pancreas cancers (top five cancer causes of death) between January 1, 2000, and December 31, 2007. The rate of radiotherapy in the last 30 days of life, by many regarded as inappropriate overtreatment, though this point of view is controversial, was $7.6 \%$. No data on reirradiation were reported in this study, and no attempt was made to develop predictive models. Before our new score can be widely implemented, external validation is necessary. In the 
future, it might become possible to study narrowly defined patient groups, if sufficiently large databases can be created. For example, Tanvetyanon et al. have published prognostic factors for survival after salvage reirradiation in patients with head and neck cancer [19]. Rades et al. have developed scores specific to metastatic spinal cord compression [20, 21], and Sperduto et al. to brain metastases [22], both related to first line treatment rather than reirradiation.

\section{Conclusions}

Prognostic factors for survival might change during the course of disease, for example, from first line to subsequent treatments. The performance of the newly developed score was promising and might facilitate identification of patients who survive long enough to benefit from palliative reirradiation. It should be validated in independent patient groups, ideally from several institutions and countries.

\section{Conflict of Interests}

The authors declare that there is no conflict of interests regarding the publication of this paper.

\section{References}

[1] E. Chow, Y. M. van der Linden, D. Roos et al., "Single versus multiple fractions of repeat radiation for painful bone metastases: a randomised, controlled, non-inferiority trial," The Lancet Oncology, vol. 15, no. 2, pp. 164-171, 2014.

[2] C. H. Son, R. Jimenez, A. Niemierko, J. S. Loeffler, K. S. Oh, and H. A. Shih, "Outcomes after whole brain reirradiation in patients with brain metastases," International Journal of Radiation Oncology Biology Physics, vol. 82, no. 2, pp. e167-e172, 2012.

[3] H. Liu, X. Zhang, Y. Y. Vinogradskiy, S. G. Swisher, R. Komaki, and J. Y. Chang, "Predicting radiation pneumonitis after stereotactic ablative radiation therapy in patients previously treated with conventional thoracic radiation therapy," International Journal of Radiation Oncology Biology Physics, vol. 84, no. 4, pp. 1017-1023, 2012.

[4] S. Mabuchi, R. Takahashi, F. Isohashi et al., "Reirradiation using high-dose-rate interstitial brachytherapy for locally recurrent cervical cancer: a single institutional experience," International Journal of Gynecological Cancer, vol. 24, no. 1, pp. 141-148, 2014.

[5] C. Nieder, N. H. Andratschke, and A. L. Grosu, "Increasing frequency of reirradiation studies in radiation oncology: systematic review of highly cited articles," American Journal of Cancer Research, vol. 3, no. 2, pp. 152-158, 2013.

[6] C. Nieder, A. Pawinski, E. Haukland, R. Dokmo, I. Phillipi, and A. Dalhaug, "Estimating need for palliative external beam radiotherapy in adult cancer patients," International Journal of Radiation Oncology Biology Physics, vol. 76, no. 1, pp. 207-211, 2010.

[7] C. Nieder and M. P. Mehta, "Prognostic indices for brain metastases-usefulness and challenges," Radiation Oncology, vol. 4, article 10, 2009.

[8] E. Chow, M. Abdolell, T. Panzarella et al., "Predictive model for survival in patients with advanced cancer," Journal of Clinical Oncology, vol. 26, no. 36, pp. 5863-5869, 2008.
[9] D. Rades, J. Dunst, and S. E. Schild, "The first score predicting overall survival in patients with metastatic spinal cord compression," Cancer, vol. 112, no. 1, pp. 157-161, 2008.

[10] D. Rades, J. Dunst, and S. E. Schild, "A new scoring system to predicting the survival of patients treated with wholebrain radiotherapy for brain metastases," Strahlentherapie und Onkologie, vol. 184, no. 5, pp. 251-255, 2008.

[11] A. B. Chen, A. Cronin, J. C. Weeks et al., "Palliative radiation therapy practice in patients with metastatic non-small-cell lung cancer: a cancer care outcomes research and surveillance consortium (CanCORS) study," Journal of Clinical Oncology, vol. 31, no. 5, pp. 558-564, 2013.

[12] B. A. Guadagnolo, K.-P. Liao, L. Elting, S. Giordano, T. A. Buchholz, and Y.-C. T. Shih, "Use of radiation therapy in the last 30 days of life among a large population-based cohort of elderly patients in the United States," Journal of Clinical Oncology, vol. 31, no. 1, pp. 80-87, 2013.

[13] J. D. Murphy, L. M. Nelson, D. T. Chang, L. K. Mell, and Q.-T. Le, "Patterns of care in palliative radiotherapy: a population-based study," Journal of Oncology Practice, vol. 9, no. 5, pp. e220-e227, 2013.

[14] N. S. Kapadia, R. Mamet, C. Zornosa, J. C. Niland, T. A. D'Amico, and J. A. Hayman, "Radiation therapy at the end of life in patients with incurable nonsmall cell lung cancer," Cancer, vol. 118, no. 17, pp. 4339-4345, 2012.

[15] C. Nieder and J. A. Langendijk, Eds., Reirradiation: New Frontiers, Springer, Berlin, Germany, 2011.

[16] E. Chow, K. Fung, T. Panzarella, A. Bezjak, C. Danjoux, and I. Tannock, "A predictive model for survival in metastatic cancer patients attending an outpatient palliative radiotherapy clinic," International Journal of Radiation Oncology Biology Physics, vol. 53, no. 5, pp. 1291-1302, 2002.

[17] E. Chow, M. Abdolell, T. Panzarella et al., "Validation of a predictive model for survival in metastatic cancer patients attending an outpatient palliative radiotherapy clinic," International Journal of Radiation Oncology Biology Physics, vol. 73, no. 1, pp. 280-287, 2009.

[18] S. Gripp, S. Mjartan, E. Boelke, and R. Willers, "Palliative radiotherapy tailored to life expectancy in end-stage cancer patients: reality or myth?" Cancer, vol. 116, no. 13, pp. 3251-3256, 2010.

[19] T. Tanvetyanon, T. Padhya, J. McCaffrey et al., "Prognostic factors for survival after salvage reirradiation of head and neck cancer," Journal of Clinical Oncology, vol. 27, no. 12, pp. 19831991, 2009.

[20] D. Rades, T. Veninga, A. Bajrovic, J. H. Karstens, and S. E. Schild, "A validated scoring system to identify long-term survivors after radiotherapy for metastatic spinal cord compression," Strahlentherapie und Onkologie, vol. 189, no. 6, pp. 462-466, 2013.

[21] D. Rades, M. Hueppe, and S. E. Schild, "A score to identify patients with metastatic spinal cord compression who may be candidates for best supportive care," Cancer, vol. 119, no. 4, pp. 897-903, 2013.

[22] P. W. Sperduto, S. T. Chao, P. K. Sneed et al., "Diagnosisspecific prognostic factors, indexes, and treatment outcomes for patients with newly diagnosed brain metastases: a multiinstitutional analysis of 4,259 patients," International Journal of Radiation Oncology Biology Physics, vol. 77, no. 3, pp. 655-661, 2010. 


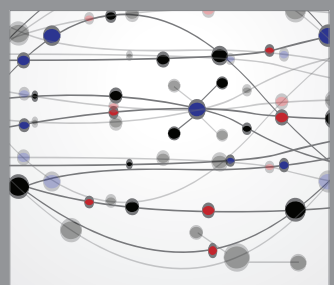

The Scientific World Journal
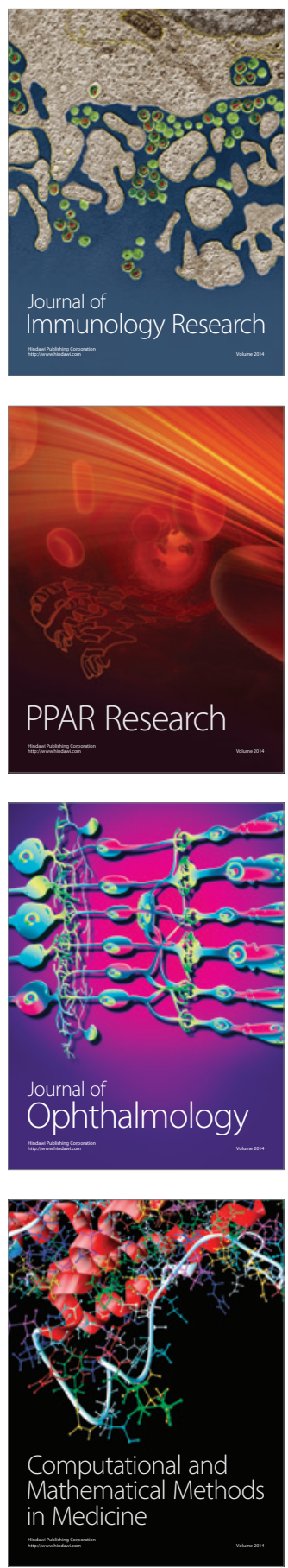

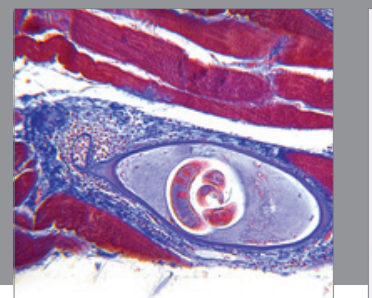

Gastroenterology

Research and Practice
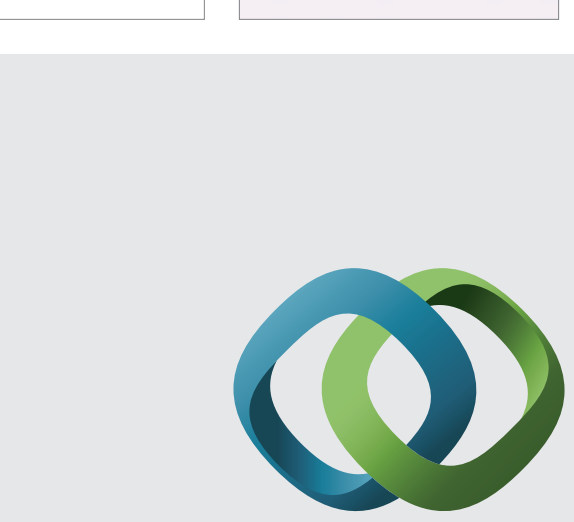

\section{Hindawi}

Submit your manuscripts at

http://www.hindawi.com
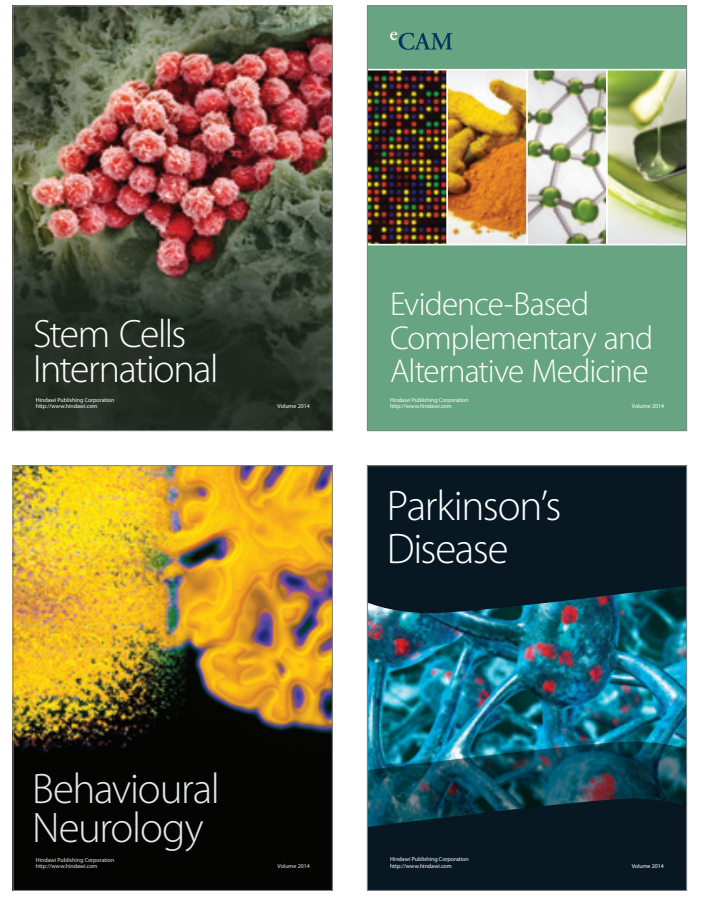
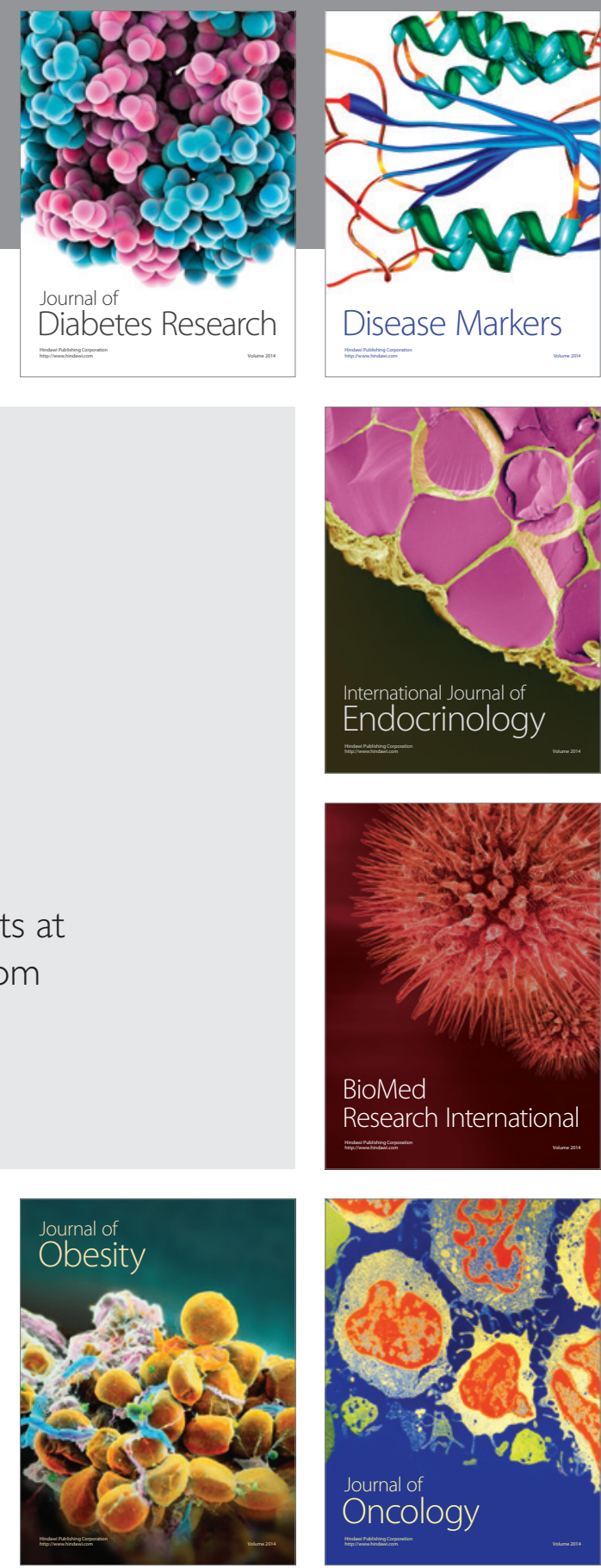

Disease Markers
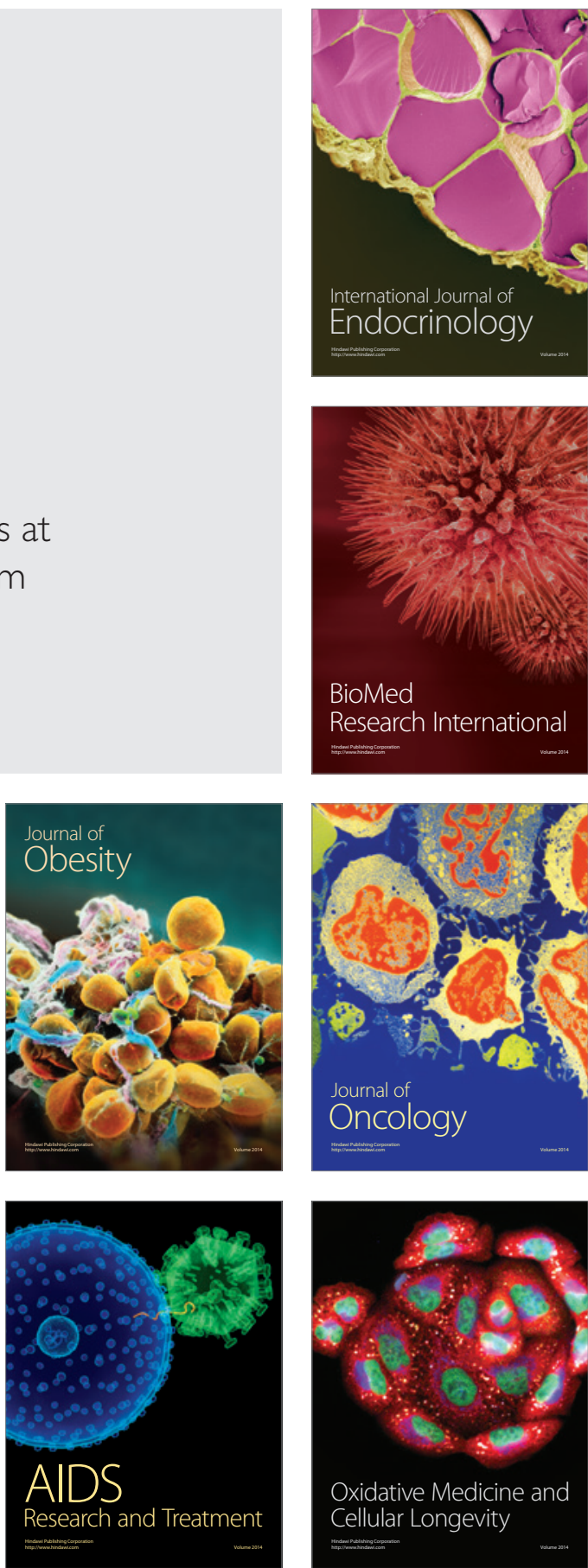